Access to this work was provided by the University of Maryland, Baltimore County (UMBC)

ScholarWorks@UMBC digital repository on the Maryland Shared Open Access (MD-SOAR) platform.

Please provide feedback

Please support the ScholarWorks@UMBC repository by emailing scholarworks-group@umbc.edu and telling us what having access to this work means to you and why it's important to you. Thank you. 


\section{Perspectives of Bioartists and Community Lab Organizers on Working with Living Organisms}

\section{S. NISA ASGARALI-HOFFMAN}

Information Studies, University of Maryland (UMD)

FOAD HAMIDI

Information Systems, University of Maryland, Baltimore County (UMBC)

There is increasing interest within the HCI community about working with living organisms in the design of interactive systems. Bioartists and community lab participants have worked with living organisms for decades. Their motivations for doing so include artistic expression, design innovation, and activism. We interviewed 12 artists, community lab organizers, and researchers who work with or facilitate work with living organisms. Participants expressed perspectives on working with living orga nisms and described bioart as an effective practice for engaging and informing the public, fostering transdisciplinary collaborations, and for facilitating inspiration and learning from organic processes. They also discussed questions of agency and consent, among othe $r$ ethical issues in this context. Based on our findings, we present future directions to investigate the potential of hybrid living media interfaces to engage and educate human users, open up possibilities for transdisciplinary collaborations, and participate in ethical dialogues on emerging technologies in a new way.

CCS CONCEPTS • Human-centered computing • Human computer interaction (HCI) • HCI theory, concepts and models

Additional Keywords and Phrases: Living organisms, bioart, transgenic art, DIYbio, community science, biotechnology

\section{ACM Reference Format:}

First Author's Name, Initials, and Last Name, and Second Author's Name, Initials, and Last Name. 2020. The Title of the Paper: ACM Conference Proceedings Manuscript Submission Template: This is the subtitle of the paper, this document both explains and embodies the submission format for authors using Word. In Woodstock '20: ACM Symposium on Neural Gaze Detection, June 0305, 2018, Woodstock, NY. ACM, New York, NY, USA, 10 pages. NOTE: This block will be automatically generated when manuscripts are processed after acceptance.

\section{INTRODUCTION}

In her CHI 2017 keynote, Neri Oxman described her process of combining materials science, digital fabrication technologies, and living organisms to explore material ecology through design. Her presentation signaled the growing excitement in an emerging area of HCI research that studies the design and evaluation of interactive systems that incorporate living organisms, such as plants [21], bacteria [35] or fungi [19], among others [39]. Recent projects have explored the functional and aesthetic qualities of these hybrid Living Media Interfaces (LMIs) [39] in educational and therapeutic applications [19,35], for data visualization [14], and more rarely in interactive art 
installations [1]. This growing body of research has shown that LMIs can support engaging and meaningful interactions, while also raising ethical and practical concerns.

Despite this potential, previous HCI research has yet to explore in depth the perspectives of expert bioartists, who work with living organisms as part of their creative practice, DIYbio researchers, and community lab organizers who facilitate the participation of amateur designers and artists in creative practices that involve working with living organisms and biotechnology. While there has been research on DIYbio and the promising collaborations between HCI researchers and DIYbio participants [15,27-29] there has not been much exploration into the unique qualities associated with artistic practices that could be beneficial for the HCI audience. Artistic exploration is unique in its focus on cultural production and creative inquiry. Bioartists mirror the growing public awareness, excitement, and fears of the capabilities of biotechnology. They explore these by engaging in what De Menezes terms "art research," where artists move past the position of observer or commenter on the scientific research process to immerse themselves in a new form of research and knowledge production in its own right, with a different epistemological stance and research goals than a biologist [38]. Vaage describes how the embodied response to visceral, living artworks can induce reflection on technologies and our relationship to other living beings in a different way [48]. Through their direct experience working with biological organisms and reflecting on the practical, aesthetic, ethical, and ontological implications and possibilities of their work, these experts can provide insights to inform the exciting and emerging work situated at the intersection of art, biology, and HCI.

We present findings from an interview study with bioartists, community lab organizers, and DIYbio researchers working with living organisms to better understand their perspectives on possible future opportunities and challenges at the intersection of bioart and HCI. Our participants described living organisms as inspiring sources of knowledge and saw working with them as an effective approach to engaging the public with biological inquiry and fostering transdisciplinary collaborations that transcend disciplinary bounds []. They further outlined some of the ethical dilemmas working in this space, both with respect to deciding how to incorporate a living organism into an artwork and also assessing the possible outcomes of their practice within an ecosystem and offered possible directions for future exploration. Perhaps most importantly for the HCI community, they discussed their roles as cultural producers that use artful making as a means of starting critical dialogues about the potential uses of biotechnology.

\section{BACKGROUND: A BRIEF OVERVIEW OF BIOART}

Bioart is a contemporary art movement that is comprised of a hybrid of artistic and scientific practices which engage in the use of biomaterials (i.e. living cells, tissues, organisms) and scientific techniques, protocols, and tools [5,6]. A key example of a bioart piece is Genesis by Eduardo Kac, in which he developed and displayed transgenic bacteria with modified DNA that included a sequence of symbols encoding a line from the Book of Genesis [22]. Audience members could remotely shine an ultraviolet light on the bacteria to cause mutations in their DNA, impacting the encoded line. Another key example is Nature? by Marta De Menezes, in which the DNA of live butterfly was modified to result in new patterns on their wings [37]. In other projects, performance artist, Stelarc, grew an ear-shaped sculpture out of human tissue to be installed on his arm, and artistic collaborators Catts and Zurr grew "wings" from pig bone marrow stem cells on degradable structures in the shape of wings [40]. The terminology associated with this movement can seem unclear to an audience unfamiliar with it. Therefore, we would like to offer a set of terms and definitions, as well as some caveats associated with them. 
Bioart - an art movement which "situates the process of artistic enquiry within the realm of molecular biology and new biotechnological practices" [2]. While we have chosen to primarily use this term in this paper (except when participants preferred otherwise), it is currently debated and there are several others that are also used by artists to refer to their practice, including biological arts, hybrid art, and transgenic art, among others $[7,10,23]$.

Biodesign - designing and building things with biology [41].

Biomaterials - materials that are alive, including living cells, tissues, and organisms [44].

Living Media Interface (LMI) - "interfaces that incorporate living organisms and biological materials into artifacts to support interaction between humans and digital systems" [39].

The glossary above is provided in order to better ground the HCI audience in an understanding of these terms. However, as mentioned above these definitions are not rigid and there is debate amongst bioartists on how they should be defined $[42,48]$. Even amongst our participants, some acknowledged a fluidity and blurring of the lines between bioart and biodesign, while some maintained that these areas of exploration were definitively distinct. We see these ambiguities is a sign that the field is constantly shifting, and that the definitions are not static.

While recent advances in synthetic biology have opened up possibilities for artistic exploration with living organisms, artists have been exploring this space at least since the 1920s [40]. Alexander Fleming, who is credited with discovering penicillin, created paintings of stick figures, soldiers, and houses on paper using bacteria as a medium in the late 20s [51]. In the 1930s, artist Edward Steichen manipulated the chromosomes of delphiniums using a common crossbreeding technique for creating mutant plants, resulting in oversized leaves [44]. More recently, many artists and performers, such as Eduardo Kac, and Oron Catts and Ionat Zurr, utilize advances in biotechnology to enable the incorporation of living organisms in works of art [39,44,48,51].

Bioartists use living media as a part of their art practice for different purposes. Some artists use it as a way to address wider biopolitical issues such as the relationship of human beings to other living things, human body enhancement, the future possibilities of food production, and the narratives of technosolutionism [48]. Other artists use living media to bring attention to problematic applications of biotechnology $[39,48]$. Bioart is often an exploratory space wherein bioartists develop visionary uses for new biological and technological practices $[9,11,16]$. Other artists use it to explore larger questions of access and ethics $[13,39,51]$, such as whether as a society we should be allowed to control or manipulate life, who should have this control, and what are the potential impacts of utilizing emerging biotechnological techniques. No matter the reasoning for working at the intersection of art and technology, the novel creations of the bioart movement address the ontological murkiness associated with defining new forms of biotechnical life [32]. In this paper, we argue for the relevance of these experiences for the HCI community, both as a source of knowledge and inspiration for the creation of future technologies, and as a rich and underexplored site for transdisciplinary collaboration and cultural production.

\section{RELATED WORK}

In recent years, a growing body of research in Human-Computer Interaction (HCI) has emerged that studies the possibilities of using living organisms in the context of interactive systems (e.g., $[17,19,35,50]$ ). The majority of these projects are focused on the functional and design-focused possibilities of hybrid systems that combine living and digital components [39]. As we will describe in the following subsection, these efforts largely fall into the intersection of HCI and biodesign [41]. There are fewer projects that to date that have focused specifically on understanding questions at the intersection of bioart and HCI. As mentioned previously, though some may argue to define biodesign and bioart as distinct areas of inquiry, it is important to review the HCI literature that addresses 
both biodesign and bioart because there is such a small body of HCI literature that addresses the intersections of biotechnology and art and design. More broadly, there has been research on the intersection of art and biotechnology in fields outside of HCI. In the following subsections, we first review research on hybrid interactive systems that combine living and digital components, with a focus on the current state of knowledge regarding their contribution to HCI. Next, we describe efforts that have attempted to bridge bioart and HCI with a view of understanding what transdisciplinary possibilities such bridging may bring about. We then describe relevant discussion on the ethics of working with non-human living organisms. Finally, we address the broader non-HCI bioart research in other disciplines that may offer key insights and provocations for the HCI community.

\subsection{Living Media Interfaces and Interactive Platforms}

A small but growing body of research in $\mathrm{HCI}$ has been investigating the possibilities and challenges of incorporating living organisms in the design of living media interfaces (LMIs) which Merritt et al. defined as interactive interfaces that combine living organisms and digital components [39]. HCI research has investigated how to incorporate a range of organisms, including plants (e.g., [14,21]), animals (e.g., [45]), fungi [19], eubacteria (e.g., E. coli) [11,22], and protists (e.g., Euglena gracilis) [35], in the design of interactive systems.

The following three examples demonstrate recent LMIs from the HCI community: Infotropism consisted of a corn plant placed between two directional lights, one corresponding to a trash bin and the other a recycling bin [21]. The corresponding light would turn on whenever a bin was used, causing the plant to respond to the light and lean towards the more used bin over time. In Babbage Cabbage, the color of cabbage plants was manipulated by changing the $\mathrm{pH}$ level of a solution in which they were placed to reflect different values of statistical data dynamically collected from the Web [14]. Finally, in the Trap It! museum installation, users could view Euglena gracilis microorganisms through a magnifying glass and interact with them through a touchscreen and optical hardware [35].

Beyond designing and evaluating artifacts, other projects have focused on creating tools and toolkits to facilitate the creation of LMIs. For example, Yao et al. explored the potential of living Bacillus Subtilis natto cell as a humidity sensitive nano actuator that may be used as a prototyping component to enable a range of responsive projects [21]. In another project, Gome et al. modified a commercially available robotic arm using custom 3D printed parts, a modified pipette, and a visual block-based programming interface, to make it suitable for handling liquids with biomaterials, microorganisms and cell cultures by bioartists and biodesigners [17].

Through their focus on functionality and exploring affordances for user experiences, most existing LMIs are situated in the intersection of biology and design, rather than within the creative and artistic practices of bioart.

\subsection{Understanding DIYbio Practices}

Another body of HCI research has focused on understanding and participating in DIYbio communities [26-29]. Kuznetsov et al. define DIYbio as "a nascent movement within the broader maker culture, aimed at enabling public participation in biology outside of professional laboratory settings" [27]. DIYbio participants often work in community lab settings. In a study of DIYbio initiatives around the world using interviews with DIYbio practitioners, Kuznetsov et al. found that this community operates across intersections - or seams - between an array of stakeholders, resources, and interests [29]. They also recognized parallels between the evolution of DIYbio as a grassroots community and how DIY hacker/maker cultures have shaped and are shaping different initiatives within HCI. The researchers identified several areas of future exploration at the intersection of HCI and DIYbio, including 
developing tools for transdisciplinary collaboration, mechanisms for external communication and hybrid bioelectronic assemblies [29]. They presented functional prototypes to illustrate each area, including an interactive device for viewing bioluminescent algae. In another project, Kuznetsov et al. explored the possibilities of several pieces of existing and customized biology lab equipment, including an OpenPCR and a Pearl Blue Transilluminator, for engaging non-biologist members of the public in DIYbio prototyping and exploration [28].

Given the educational premise of many community lab and DIYbio organizations, it is not surprising that previous research efforts have also focused on understanding the learning outcomes of engaging in these practices on youth and adults, with a view of understanding the differences and overlap between traditional maker activities and biomaker activities for education [24]. For example, Kafai and Walker presented ways to bring "constructionist activities into making with living materials" [25]. They proposed that the creative and experimental methods utilized in the maker movement should be applied to biodesign. Grote et al. described their experience designing an interface to assist synthetic biologists through complex bio-design processes [18]. They also emphasized the facilitation of constructivist learning as one of their goals in designing this interface and evaluated their approach through user studies with two university-level teams who were participating in the iGem DIYbio competition [18].

\subsection{Bioart Intersecting with $\mathrm{HCl}$}

A few recent projects have more directly explored the intersection of bioart and HCI. Alistar and Pevere created a tangible bioart installation that embedded the memories of an elderly participant that were recorded, transcribed and encoded into DNA code before being inserted into the cells of Komagataeibacter rhaeticus bacteria [1]. In addition to describing their process of encoding text information into the DNA of living organisms, the authors discussed the characteristics of living organisms as tangible living media that in comparison with digital physical computing components, may create a sense of relatability in human audiences, provide opportunities for rapid replicability (through cellular reproduction) as well as slower response time and increased chance of contamination. The authors encourage further explorations in this area and identify the need for transdisciplinary collaboration and domain knowledge exchange as both a challenge and opportunity for the HCI community.

Kuznetsov et al. presented an autoethnographic study of their process of transforming a university HCI lab into a BSL-1 (biosafety level 1) DIYbio facility and organizing a weeklong bioart workshop for youth [27]. During the workshop, youth created microbial art (also known as Agar Art [2]) by transferring living microorganisms that express colors according to creative stencil outlines to lab plates containing a growing agent (i.e., Agar). The authors observed that interacting directly with living materials afforded "new ways of seeing" and made the youth aware of a certain form of non-human agency in how the living organisms responded to each other and other materials used in the workshop over time.

As a final example, Hamidi and Baljko created a LMI which incorporated a living colony of oyster mushrooms in an interactive installation in which the mushrooms' growth rate over several days was impacted by how much audience members interacted with a digital application narrating a story about the organism. The project was described as an edible living media sculpture that grows through audience member interaction [19].

This mode of experiential inquiry is closely connected to the notion of Speculative Design within HCI which views design as a form of inquiry, where knowledge making is the intended outcome rather than to yield products $[4,34]$. According to Bardzell, the importance of this mode of design within HCI is to "share design challenges, reframe our design thinking, and/or propose alternative but plausible formulations of the future, where design itself can contribute new knowledge" [4]. This approach, similar to viewing bioart practices and artifacts as modes 
of cultural inquiry, views creative practices as venues for knowing and understanding, "asserting that objects themselves can serve as a medium for thought" [4].

\subsection{Ethical Considerations}

Finally, efforts have been made in the HCI research community to address some of the ethical questions that arise from working with living organisms. For example, Harvey et al. presented a discussion on the implications of games that incorporate living insects [20]. They argued that, at the very least, designers need to consider whether the system would cause suffering, especially in the case of sentient beings, and how beneficial its outcomes are for humans. Similarly, Fawcett and Dumitriu recommended carefully weighing the benefits and potential dangers of displaying microbiological bioart and specifically considering the overall aims of each project and whether they require or are enhanced by the use of the actual media [13].

More nuanced discussions have arisen within the Animal-Computer Interaction (ACI) community, which has largely advocated for the adoption of participatory or "user-centered" approaches towards developing technologies for and with animals [36,49]. Despite their appeal, these approaches are controversial. For example, in the absence of a shared language between human and non-human animals Lawson et al. proposed the use of a speculative design process in which imaginative future design scenarios can be used to gain insight into the potential impact of technology designed for animals [34]. While the majority of discussion in the HCI community has focused on ethical implications of working with animals, bioartists and bioethicists have also extensively explored ethical questions that may arise when working with plants, bacteria and other organisms, for example when considering when genetically-modified plants interact with the natural environment $[10,48]$.

\subsection{Bioart Research Beyond the $\mathrm{HCl}$ Community}

There has been attention from several research communities on both the potential and implications of the bioart movement. Much of this research comes from critical media studies and sociotechnical studies [30-33,44,47]. For example, Lapworth explores the ontogenetic possibilities of bioart, past thinking through the meaning of art, life and the sciences, but to thinking through the reconfiguration of the subject; the material production of new subjects and worlds [32]. Lapworth also posits that art-science collaborations not only enhance the public awareness of new technologies, but develop what Simondon termed new technical mentalities, or more material transformations in our embodied capacities for perceiving and affectively engaging with technologies [33]. Straughan focuses on tacit knowledge, specifically through the embodied practice in the lab space to "think through the roles of the somatic senses and non-human others, as well as artists themselves, in the acquisition of knowledge" [47]. Radomska argues that thinking with and through the feminist technoecologies of bioart allows us to reimagine the ontology of life, including our dichotomies of living and non-living [44].

There is a body of research on bioart proliferated by bioartists themselves [3,10,38,52]. Zurr and Catts have written about how their work with the Tissue Culture \& Art Project allows them to explore society' s changing definitions of life and the semi-living, and critique how these definitions adapt to create inclusionary and exclusionary forms of citizenship [52]. They have also interrogated how incorrect use of scientific terminology in bioart-related research furthers public misunderstanding of science and reinforces the dominant narratives about the life sciences promoted by biotechnological industries [10]. De Menezes advocates for the artists as researcher, stating that bioartists are not just artist or just scientist, but a hybrid of both, wherein the artist takes on the challenges of developing new practices, new media, and new methods to manipulate materials for artistic 
expression rather than to fulfill scientific goals [38]. Angleton also analyzes new definitions of artwork when art is created using a laboratory, and discusses the importance of collaboration with scientists in this process[3]. Moving past the ethical inquiry inherent in working with living matter, bioartists utilize their artistic explorations to explore deeper ontological questions, challenging our definitions of life, agency, and power [31,52].

\subsection{Summary of Related Work}

The majority of the work exploring the intersection of bioart, biodesign and HCI has focused on developing hybrid artifacts (e.g., [14,19,35]), tools for creating hybrid systems [17,50], and understanding amateur DIYbio practices and outcomes [26-29]. Additionally, a body of work is emerging that focuses on the ethical and practical questions of designing with and for non-human living organisms [20,34,36]. Finally, there is a body of work in the arts and humanities that explores how bioart explores ontological questions $[10,30,31,33,52]$. Previous research has not yet investigated the perspectives of bioartists, community lab organizers facilitating bioart activities, and researchers working in this area with an aim to inform, shape and influence transdisciplinary HCI practices. These perspectives embody a rich tradition of experiential hands-on interaction with living organisms for creative and artistic aims as well as research that critically engages with these creative practices. Understanding these perspectives may both inspire the creation of future hybrid interactive systems, and perhaps more importantly, point to new ways of interpreting and interrogating emerging technologies.

\section{METHODS}

\subsection{Participants}

We conducted interviews with 12 professional artists, community biology lab organizers and educators who work with living organisms in their practice. Table 1 shows participants' demographic and professional information. The participants represented a broad range of practitioners with intersecting professional roles, including professional bioartists (2), bioartists/educators (3), community biology lab organizers/educators (2), and researchers working with living organisms (1). We recruited participants from different levels of experiences, age groups and gender identities. All but one participant (P2) are currently based in the United States. Many of our participants described multifaceted professional identities. For example, several bioartists described how they also teach art, biology, or both and thus see themselves both as artists and educators.

We recruited participants through a combination of personal and local artist community connections, online searches of bioartists and snowball sampling.

Table 1: Participant Information

\begin{tabular}{cllllll}
\hline Participant ID & Participant Name & Professional Role(s) & $\begin{array}{l}\text { Years of } \\
\text { Experience }\end{array}$ & $\begin{array}{l}\text { Age } \\
\text { Group }\end{array}$ & Race/Ethnicity & $\begin{array}{l}\text { Gender } \\
\text { Identity }\end{array}$ \\
\hline P1 & Jen Liu & Researcher & 6 & $20 \mathrm{~s}$ & Asian American & female \\
P2 & Steve Bradley & Artist/educator & 10 & $60 \mathrm{~s}$ & White & male \\
P3 & Lisa Moren & Artist/educator & 1 & $50 \mathrm{~s}$ & White & female \\
P4 & Lisa Scheifle & Advocate & 7 & $40 \mathrm{~s}$ & White & female
\end{tabular}




\begin{tabular}{|c|c|c|c|c|c|c|}
\hline Participant ID & Participant Name & Professional Role(s) & $\begin{array}{l}\text { Years of } \\
\text { Experience }\end{array}$ & $\begin{array}{l}\text { Age } \\
\text { Group }\end{array}$ & Race/Ethnicity & $\begin{array}{l}\text { Gender } \\
\text { Identity }\end{array}$ \\
\hline P5 & Dan Grushkin & Advocate & 11 & $40 \mathrm{~s}$ & White & male \\
\hline P6 & Ryan Hoover & Artist/educator & 7 & $40 \mathrm{~s}$ & White & male \\
\hline P7 & Mary Maggic & Artist & 7 & $20 \mathrm{~s}$ & Asian American & non-binary \\
\hline P8 & Rian Hammond & Artist & 7 & $20 \mathrm{~s}$ & White & non-binary \\
\hline P9 & Anonymous & Artist/Researcher & 8 & $30 \mathrm{~s}$ & declined to answer & female \\
\hline P10 & Tagide deCarvalho & Artist/Researcher & 3 & $40 \mathrm{~s}$ & White & female \\
\hline P11 & Justice Walker & Advocate/Researcher & 5 & $30 \mathrm{~s}$ & $\begin{array}{l}\text { Hispanic/Black } \\
\text { American }\end{array}$ & male \\
\hline P12 & Carolyn Angleton & Artist & 8 & $50 \mathrm{~s}$ & White American & female \\
\hline
\end{tabular}

\subsection{Data Collection and Analysis}

We conducted semi-structured interviews, lasting between 48 to 90 minutes. We also asked participants to fill out a short survey asking for their demographic and background information. We used two variations of the interview protocol, one for bioartists and another for community lab organizers. We piloted the interview with two participants to refine the questions and interview flow. In the interviews, we asked participants about their artistic practice or community organizing activities, their motivations for working with living organisms, their ideas about the role of digital technology in relation to their work, and future directions they believe bioart and DIYbio are headed towards. Additionally, we asked about participants' opinions about emerging analogies between digital and organic processes, such as gene editing, cutting and pasting DNA, and describing an organism as a computer or machine $[9,28]$.

We asked participants' preference for staying anonymous or share their names and affiliation since they were discussing their creative practices. We were given permission for this provision by our university's Institutional Review Board (IRB) that also approved our study protocol prior to data collection. Interviews were conducted inperson and through video conferencing. All interviews were transcribed, and transcriptions were used for open and axial coding. We employed an inductive thematic analysis to identify and synthesize themes in the data. The analysis resulted in four themes and nine subthemes that we will present next.

\section{FINDINGS}

Our findings showed that participants viewed artistic activities with living organisms as a site of transdisciplinary collaboration as well as an effective tool for engaging and educating the public. Further, participants described how working with living organisms can be inspiring and lead to new beneficial knowledge. They also shared their views on questions of agency and consent in relation to non-human living organisms. Finally, they reflected on the possibilities and challenges of designing with living organisms. 


\subsection{Bioart as a Tool for Engagement and Collaboration}

\subsubsection{Bioart Increasing Public Knowledge and Awareness}

Many participants described they use bioart as a tool for education and raising public awareness. P11 spoke of education as a main priority for the work that they do:

"I think number one is I'm a researcher and so, I think a lot about how education could be supported in these spaces or exist in these spaces. Um, with my researcher hat, that's what I think about. But then in my sort of community organizer or organizer or leader role, uh, contribute to bringing groups together to talk about or to engage with ideas related to community and biology and education."

Another participant's main motivation was equipping the general public with knowledge, thereby empowering them with scientific understanding that could lead to increased agency and informed action. P7 spoke of the empowerment of acquiring intimate knowledge of hormones. Their work started with the political motivations of demanding the right to access birth control, contraceptive therapy, and gender transition therapy. Through their research, they learned about what they described as a system of policing hormones to support a binary system of gender, resulting in a form of "molecular colonization," or "hormone pollution" as a byproduct of capitalism and the agricultural, petrochemical, and pharmaceutical industries. They were perplexed with questions around agency: how much consent do we have in the ways in which our bodies are policed through hormones? They believe that this system can be disrupted as people reclaim their agency, and they aid in this by offering workshops where participants can learn how to test for hormones in their urine and gain an understanding of what their findings mean:

"When I give workshops, I want people to walk away with the knowledge of how to try it at home themselves... I think it could be really empowering for people."

P7 further described that they aim to "bring awareness and the demystification of molecules" through this process to members of the public.

These sentiments were also echoed by P6 who viewed bioart as a way to gain knowledge about socio-political issues:

"I could look into it and see, you know, the business practices of a company like Monsanto were really problematic. But I didn't really know exactly what a GMO is and how it's made. So, I wanted to learn more about this... And then right around that time I heard about [local community lab focused on bioart and biodesign] opening up... I could literally just go learn about GMOs and figure out what this means ... Understanding what actually is being made, where potential risks are, and understanding it's different if you're engineering an organism so that its roots go a little bit deeper into the ground and they're more drought resistant versus if you're engineering organisms you could just indiscriminately spray pesticides on."

By participating in bioart and biodesign workshops and information sessions P6 expressed an ability to make informed decisions and take stronger social and political stances with regards to a specific application of biotechnology. They are now working on developing ways to 3D print with biomaterials in order to explore ways to create structures through new biofabrication techniques. 
This concept of fostering greater public understanding of what is happening in the scientific and biotechnological world was also present in our conversations with DIYbio organizers. P4, who is the executive director of a local community lab and an associate professor of biology at a local university, also spoke of the power of advancing scientific inquiry in the community.

She described a workshop where youth learn about genetically modifying yeast and bacteria, so they express different colors when growing and then use these organisms to create a piece of visual artwork. She stated that the strength of the workshop is in "using art to kind of capture [the youth] and let them see that the science is much more accessible and engaging than maybe what they've been doing in class... so long-term that changes their perception of science and kind of gets them back into the creative aspect of science... we want to make science fun again, to really get people to realize that it's accessible, it's doable."

P11 spoke about the unique qualities and affordances of community lab science experiences compared to traditional scientific learning spaces.

"I especially appreciate moments when we can get someone to think conceptually differently about an idea or something. And so bioart represents an example of that, right? Like the idea that you could use an organism to create something artistic that is like sort of a, a mashup of two concepts to create something novel... And in the same way you can do that about education... it's really disrupting how we do traditional science education and in a way that might be more inclusive. And so it's this element of like, doing something, shifting the way we've used something. Or a paradigm shift if you want."

P4 stressed the importance of engaging people in an understanding of science because "ultimately all the money for science comes from the public. They're in charge of funding. And if we want to get the best of scientific research funded, we need the public to understand it and understand what we're doing and why we're doing it."

Finally, P4 also described how engaging with scientific principles can help people to develop a greater understanding of their more immediate world, such as their healthcare or the ecological environment:

"I think also reminding people that science impacts their daily life, and that it is accessible, and it is understandable... Maybe even in their own healthcare, they won't be as intimidated to find out more because they don't feel so intimidated by science as a process."

Thus, participants saw bioart as an effective and novel tool for increasing public engagement with contemporary scientific, artistic, and socio-political topics.

\subsubsection{Bioart as a Site of Transdisciplinary Collaboration}

The importance of transdisciplinary artistic and scientific collaborations came up repeatedly in the interviews. All participants agreed that transdisciplinary collaboration allowed for the inclusion of more diverse and critical voices which could often facilitate working through ethical considerations for a project. Several of the participants described successful and ongoing collaborations with scientists, and scientific organizations, including P2 (Baltimore Underground Science Space and Institute of Marine and Environmental Technology), P3 (Institute of Marine and Environmental Technology), P6 (Baltimore Underground Science Space and University of Maryland Center for Environmental Science), and P12 (American River College Biotechnology and Art Collaborative (ARCBAC) and SacBioArts). 
P4 stressed the importance of scientists like themselves working with artists to merge their diversity of perspectives in order to solve problems.

"There are people who are legitimately talking about bringing back wooly mammoths and things like that. So, I think on the one hand it's a more interesting time because we have to talk to the ethics people, we have to talk to the public, we have to engage everybody. We have to engage the artists to kind of open up our understanding of what might be possible, right? To push us to see the possibilities. But I think as scientists ourselves, we have to be more creative. We can change things now. You know, we don't just have to find out about the natural world as it exists, we can change it. And so we have to think in new and more creative ways and the artists can help us with that."

P2 is an artist that works closely with scientists and described how their collaborators do not share the same concerns as them when working with particular organisms. When asked about how they felt about taking organisms out of their natural habitat in order to include them in an installation, P2 answered:

"I have mixed feelings. I had ethical issues. The scientists don't feel that as much as I probably do because they're around that all the time."

He further described a project that involved putting vinyl discs in bodies of water to see how underwater organisms interact with them. He spoke about the ethical dilemma he felt about using one of the discs for an art installation, knowing the organisms would probably die after being transplanted from the Chesapeake Bay to a water tank:

"And I was sort of wondering what they would think about me using one of the vinyl discs [for my installation]. [The scientist] didn't even hesitate. He said, 'Well it's funny you bring that up because I just dropped one in the Inner Harbor for you.'”

P2 went on to describe his surprise that the scientist he was collaborating with did not have the same internal struggle he had had in deciding whether to use one of the discs not for scientific research, but to create art.

$\mathrm{P} 4$, who serves as a community organizer and is also a scientist by training, echoed similar ethical concerns when working with living material:

"I think part of the [debate on] ethics is you always have to respect that material, right? It's not a material, it's a living organism. ... Certainly, if you're religious, you would say it's part of creation. So, I think we have to be respectful in how we use it. The more you get into [working with] animals, the more cautious and careful we have to be. I buy glow fish from Petco, which are engineered to glow pink and green and all of that. And I think it's relatively harmless, but on the other hand, should we be doing that? You know, should we be manipulating stuff just cause it looks pretty to us? I think there's some gray areas when you start doing a lot of that. It just becomes a bit abusive I think."

Other participants also mentioned the importance of interrogating their artistic practices when working with living organisms and described how their critical and philosophical stance can complement the often practical approaches of their scientist collaborators. In this way, the participants believe they contributed positively to the development of more nuanced conversations in the scientific community. P12 spoke of this, stating, "as an artist in terms of whether you're doing cutting edge research, I'm not sure that you always are. I think you're less likely to 
do that than actual scientists who have been trained in that. But I think you can intersect and have conversations with scientists in a way that enlightens and kinda ask things from a different perspective." P7 described the differences they saw in the scientific and artistic ways of thinking:

"[This is a] reason why even though I have a biology background, I didn't become a biologist. I decided to become an artist so I can just stay in this interdisciplinary field. I can expect [critical reflection] from an artist because an artist is supposed to be thinking about their work from all different angles. But I have a lesser expectation for a scientist because I know in that kind of scientific field and the way that the scientists are socialized, I feel like they would think that only to check a box or something on like the list of things you should ethically do. But I also don't know how much in control they are of their own experiments because a lot of scientists are working under their Principle Investigators and they don't have any voice in the experiment. So yeah, I just felt like this scientific field doesn't have a lot of freedom."

This lack of faith in positivist scientific systems of knowledge-making is what led P7 to develop their workshops to empower participants to learn about the ways that political and social systems of power exert control over their bodies. Their constructivist approach to science allows them to share scientific practices with workshop participants to deconstruct traditionally accepted notions of the objectivity of science.

Overall, participants highly valued the inter- and transdisciplinary nature of their work that both necessitated the navigating of multiple epistemologies, especially when collaborating with scientists, and allowed for exploration of exciting areas that exist outside of disciplinary bounds.

\subsection{Living Organisms as Sources of Inspiration and Knowledge}

\subsubsection{Learning and Being Inspired by Living Organisms}

Several participants viewed living organisms as a source of knowledge and inspiration. P10 described the wonder at which she looks at the world, through the lens of biology.

"Every time I look in the microscope, or at things that I don't need a microscope to look at, I'm just fascinated with biological form and function. I think it's so exciting that I want to share it with other people. I find the natural world more exciting than an imagined world, or a fantastical world. I think we already have all the monsters, and angels and all of the strange things that you could imagine...I feel like in part with this art that I make I can share my excitement with other people, so that's why I like using biological materials."

P3 described how working with living organisms "was really about looking at the perspective of non-humans, looking at nature from a perspective of non-humans, like biomimicry... the structures in nature that can do things that humans can't do, like use less matter with more strength." She further gave an example of how the characteristics of living organisms and natural structures can inspire future design:

"[There is] this thing called 'organic differentiation', which is like the shell of a turtle, where [the shape is] repeated but it's slightly different. And it's that difference that makes it stronger. And so when you apply that to patterns in nature, it really kind of just blows away everything every designer has ever been taught about form and function in the 20th century." 
P3 was also excited about the possibilities of sustainable design that living media could afford in the future:

"I do imagine, I mean, the best world possible would be if everything around us was biodegradable, everything had a lifespan. Like in my kitchen, why couldn't these little things just last 10 years and then biodegrade, you know? When we were designing [a bioluminescent organism installation], it was just like, how can the whole world bioluminess? Can we get lamps and streetlights and instead of changing a light bulb you'd water down the saline so they don't die or whatever you do. Making the world more like an ancient world that's completely sustainable."

Another participant, P2, described how the process of working with living organisms can shift one's perspective about them:

"There's something about the challenge of keeping something alive, and learning it, about being tuned in to that living creature. I think being able to see those changes on a daily basis is really part of the main reasons why I'm interested in living things... I think having more of an openness about the complexity of the world and the difficulties of the world and not simplifying to the point where... we abuse aspects of the world, that it's really important to take care of everything and not just the things that are important to you as an individual."

In this view, a lot can be learned from observing living organisms that can be applied to problem solving in the world. For example, P2 described how they are working on a project where they study the natural water cleaning process employed by oysters to create devices that can emulate the process at scale to help clean pollution in the ocean.

P6 also explained ways in which they are drawing inspiration from living systems in order to construct new methods of fabrication:

"What's really compelling to me is the way that nature makes things, the way that living organisms make things. I'm pretty good at it; I can make things with a lot of different technologies and have really great resources like robotic tools here for making things. But there's some things that living systems make that just blow us away. Making things, at the nanoscale or sort of micro scale, we're not great at as humans. We don't do it with economy. Really building materials and structuring materials from the ground up, is a very different fabrication strategy and design strategy that are kind of like a top-down approach than we typically take. I'm very interested in tapping into that somehow and utilizing that and merging nature's ability to grow materials from the bottom up and control structure of the materials on the nano microscale. Combining that with our precision and computationally driven methods of fabrication as well. Pulling those together and bio fabrication strategies, such as bioprinting, is a really compelling space for me."

For many of our participants, the affordances of living media yield an unlimited number of possibilities for designing elegant solutions to problems. P4 expounded on the many affordances of using living media for design purposes:

"I've seen a lot with structural materials, so for instance a mushroom mycelium or natural products to make furniture and chairs and things like that. Natural dyes I think are fantastic. I've seen applications in food safety where, you genetically engineer an organism to turn a color if there was a contaminant in your 
food, so we wouldn't have to get the E. coli in the lettuce scare all the time. I think the applications are endless, if people open their mind to it."

The different ways in which participants described being inspired by working with living organisms shows that they see possible functional outcomes of their work, in addition to aesthetic ones, that in addition to bioart may also be relevant to biodesign, and design more broadly (in that they can also inform design practice that does not necessarily use living organisms).

\subsubsection{Limits of Biotechnology as Problem-solving Tool}

Participant had somewhat contrasting views on the possibilities of bioart and biodesign to address large-scale ecological problems. Several participants (P4, P2) were optimistic about the possibilities of biotechnology to address complex problems. For example, P4 stated:

"In the building, architecture community, there's been a new appreciation with all the green movement towards using woods and different composite woods and things like that. Kind of a move back to living materials. I think the whole climate thing is going to push us to think more creatively and more sustainably. Living materials are highly sustainable in many ways and fuels, biofuels, things like that. Obviously, there are other ways."

However, several participants (P1, P6, P8) were concerned about a narrative that presents biotechnology as an effective problem-solving mechanism that can address all ecological problems. They presented critiques that were wary of this narrative as a way to perpetuate green washing and capitalism. For example, P1 described:

"Mycelium packaging is a big thing and they're like, if we just use this material that can biodegrade and compost, we can just replace our plastic packaging. And in a way it's just assuming that our consumption patterns can just continue the way it is and that we don't have to change anything... Are you just kind of creating more complicated ways of like addressing a problem at the risk of just letting narratives of capitalism continue?"

P1 also continually questioned the waste of resources in the design iteration process and wondered if the end results were worth the environmental cost. She worried that there was a reliance on technology to fix problems that have been exacerbated by technology itself.

Similarly, P6 also expressed concern that people would look at biodesign as a way to counteract ecological problems without changing the patterns that have actually caused these environmental crises:

"How can we engage in this in a way where we're not just using this technology to repeat the same patterns that have gotten us into this ecological disaster that we're in?"

P8 also mused that people expect researchers and technologists to develop new and novel solutions to fix large scale problems, replacing a collective sense of responsibility for an optimistic faith in innovation:

"A lot of the issue with biotechnology or just technology in general is that everyone is invested in technology fixing every problem in the world. Like, climate change. We all could die in 10 years, well it's okay, you know, scientists and technology are just going to fix it for us. And I think that attitude is really not productive and not helpful. And I think the same could be said about genetic engineering that people 
just think, Oh, the singularity is coming and we're going to have immortality and a utopian world where all disease is eliminated because CRISPR has been discovered, and this is just not realistic... I think about the fantasy that a lot of people have right now of growing meat in a Petri dish instead of killing an animal. And I mean personally... I don't eat meat... but if that could prevent people from supporting factory farming, then great... But I think it's also in many ways, another example of this like idea that technology can save or solve every single problem and it's one of these things that is presented in this like really utopic way. People are super excited about it, but it's never really discussed that it's still dependent on having cows in captivity and collecting fetal bovine serum from their hearts. And, and so like, that's a really interesting space where I think bioartists have stepped in and kind of critiqued that techno solutionism and broadened the conversation about those things."

The differing degrees of hope and concern shared by participants show a complex relationship that they have with biotechnology, with some seeing it as full of potential for innovation in response to complex issues, and others having strong reservations about its negative environmental impact, and ethical and social implications.

\subsection{Creating with Living Organisms}

\subsubsection{Biological Organisms as Interactive Systems}

When asked about the similarities and differences between biological organisms and interactive digital systems, participants had contrasting views. P4 found the analogy useful in describing scientific processes and concepts:

"In synthetic biology... the idea is to take genes and parts of genes and to treat them as discrete units that we can recombine in much the same way an engineer would recombine things. So, the way a computer processes information and makes decisions, we think we can, we know we can get cells to do the same thing, to process information and make decisions and give us an output based on the conditions. So we always think of biology as maybe having the ability to be analogous to digital technology to do some of the same things and to mimic it, perhaps in better ways."

She went on to identify several concepts, such as "interface", "debugging" and "programming" that have practical uses when describing processes in synthetic biology. She described how these approaches show parallels between computer science and synthetic biology.

Other participants found the metaphor to be useful at times but were dubious of embracing it completely. For example, P6 stated that:

"[There is] this metaphor that a lot of people were talking about like living systems being code or DNA as code. Which I feel is true in some extents, but just a really bad metaphor in a lot of other ways, this whole notion in synthetic biology that DNA is the software, the cell is the hardware and you can just load whatever code you want into this machine... like it's putting a floppy disc in the computer. It doesn't work like that."

Going further, he related this unease to a concern about becoming detached from the consequences of working with living organisms: "I'm worried about instrumentalizing life. I think that's not something... new to humanity... but there's a different level of detachment I think that we have with these technologies that I think is worse." 
The fear of instrumentalizing life was echoed by three other participants (P8, P7, P1). P8 stated that the metaphor of an organism as a computer was quite useful in helping people to learn and understand biology, but that it should not be taken to the point where a living organism is purely an object for experimentation.

P7 also cautioned against using computing metaphors when talking about living organisms, especially in the context of scientific experimentation. Their concern was that such a metaphor might limit the perspective of practitioners and lead to a reductionist approach:

"I think we're missing that more holistic perspective when it comes to science because science is all about cutting out elements, creating a very tear out and programmable environment. Whereas in the real world nothing is ever like that. Everything is constantly mixing and cross contaminating... it's not this highly controlled... environment of a laboratory."

\subsubsection{The Agency of Living Organisms}

Several participants discussed the agency of living organism as a unique characteristic. P5, a cofounder of a community lab and the organizer of a major biodesign competition, spoke of the unique relationships that he has seen develop between artists and organisms:

"Living things have agency, so you have to collaborate with them... living things are amazing; they reproduce, they can theoretically be an infinite number of them, they self-assemble, they evolve and they adapt... organisms have their own agency, so partnering with them is different than working with other materials."

This theme of considering living organisms as collaborators rather than a material lacking agency was present in the comments of P4 who described the "unpredictable" quality of working with living organisms:

"The unpredictability of it, to a certain extent, every time you're working with something living, you're actually collaborating with it, right? You're putting your vision, you're trying to impose your vision on it, but you can't because it has its own properties that sometimes you don't understand, it's going to mutate and evolve, and colors will develop on their own time scale. So, I think that's really interesting, that idea that unlike other forms, you're dealing with something that's constantly changing and that's unpredictable. I think there's a little bit more reverence for the natural world, right? You've got to respect it as kind of a coequal partner in the creative process."

However, some participants also questioned the use of the term "collaboration" when describing the relationship between them and the organisms they work with. For example, P8 stated:

"There's something that I've also heard come up in bioart communities before, where people will be like, 'yeah, I'm collaborating with these organisms to do this thing or whatever.' And I'm like, are you collaborating? Can you use that word when an organism can't consent to the process that you're doing?"

P8 further described how the notion of consent can be problematic when, for example, we kill millions of bacteria every time we wash our hands. 


\subsubsection{Ethical Concerns of Working with Living Organisms}

Two participants (P1, P6) voiced further ethical concerns about the use of living organisms for artistic and design purposes. P1 stated:

"There's like a fine line in working with living media. At what point are you being really exploitative of the materials that you're working with?"

On a related note, $\mathrm{P} 1$ highlighted the complexity of categorizing living organisms as "media" or viewing them as material:

"I think it's important to think about what it means to interact with another living being... maybe I'm struggling with the term 'living media' cause in its own sense I'm like when does a being become media is an interesting thing."

P1 specifically expressed a concern about the ethical issues that might come up if interactive system designers utilize living organisms without considering the ethical consequences of their choices:

"I'm concerned that there's sometimes so much interest in novelty in the HCI space that with living materials entering this area, that there might be some... troubling things that happen and because there's not people who work in bioethics, let's say, or other areas that it's just not going to be addressed in a serious way."

While several participants voiced concerns about the ethics of working with living materials, many expressed dismay at the lack of nuance that is found in discussions around the ethics of biotechnology. They felt that ethics should be a broader question, not only related to working with living materials, but to sustainability in lab practices, access, biotechnology design, scientific imperialism, and agency. P1 mentioned concerns around lab practices." P6 was concerned about the lack of nuance in the discussion around ethics in bioart:

"My ethical concerns aren't just dumbed down to, should we do this or should we not do this? So much of ethics and the frameworks around bioethics in particular are really flawed and have a ton of shortcomings ... We don't have frameworks in place necessarily for engineering entire ecosystems, right? There's no little flow chart you use for that. Because these things are too complicated for that... and just figuring out what we're not doing right. Who are we not looking after? I think it's just as important of a question of, do we do this or do we not do this?"

In a stance similar to Value-sensitive Design [16] and Reflective Design [46], P6 thought that the discussion of ethics should not be limited to just the use of living organisms, but should extend to how technologies are designed and who they are designed for: "No technology is ever neutral... Technologies are made by people and those people often have specific agendas and they also often have biases that are maybe even unknown to them, that might cause them not to consider the implications of their technology, not to consider certain users, not to consider the people who don't get to be users. There's a distancing that a lot of technologists and engineers will do... to sort of not take responsibility for a [kind of] use of it. It's a combination of, what are the actual technologies that are available, and who has access to those things."

P12 also echoed this sentiment of access as an ethical concern with biotechnology, as well as the history of scientific imperialism: “... the questions that are asked in science ... a lot of that is involved in a social critique of 
how we use biotechnology and who has access to it. What type of questions are being asked with it based on who's given permission and training to understand the questions and thereby ask the question... What are some of the ethics within biotechnology? Like what are gene drives about, who's continent are they being tested on? What are the assumptions of being able to go into a community and say, we're going to test this new technology here on your population and we don't really know what's going to happen. You know, there's a long history of scientific imperialism. Those are very much questions [that] are part of my work."

P7 spoke of weighing ethical concerns with human agency. "And of course, when you're talking about active hormones and open source and all that stuff, you have to consider, well, what are the dangers of giving yourself hormones that you just made in your own kitchen. There's a lot of ethics that we need to consider $\cdots$ the risks and kind of like safety measures. But I feel like when someone takes control of their own body and performs an experiment that they designed themselves on their own bodies, I think for some people that can be really empowering. Just to be able to not rely on your doctor or your physician and just do it yourself $\cdots$ But of course, we also need to think about the ethics and the message that we're putting out there to everyone. I mean, we have to do things responsibly. We have to do things safely."

\subsection{The Cultural and Social Role of Bioartists}

Several participants commented on the unique roles of artists in society, describing how they can spark dialogue and produce of culture and use their identity to catalyze critiques of power structures through art.

\subsubsection{Identity as a Catalyst for Inspiring Critiques of Power Structures through Bioart}

Several participants acknowledged using bioart as an approach to explore and interrogate questions of identity and how it interacts with structures of power. For example, in addition to creating an exhibition specifically focusing on healing in response to femicide in her home country, P9 described how she was exploring patriarchal culture through a project with candida yeast that causes genital yeast infections:

"But I just realized how this affects me socially, sexually, and all these parts... I just realized I was under stress, and that candida, it just come up...And I just grow some candida. I got some example from my body, and I just start to research which point they are just turning our enemy, because they are already in our body... And what is the difference with my body as someone coming from [country name to preserve artist anonymity] and living in the United States?... I just realized how I have pressure on me as a society, community in [anonymized country], on the patriarchic system, because, for example, you shouldn't have sex before married and that kind of really, really heavy [cultural norms] things we have... I want to make a portrait with all of this data."

P8 also spoke about how their work was influenced by their identity as a non-binary artist:

"I would like to create a technology so that people can produce their hormones because like I want that, I'm like, this is something that I'm going to be using for the rest of my life. There are cost issues. There are shortages often of the safest and most effective forms of Estrodiol. Um, and I think one of the issues is that because transgender people are such a small minority in society, uh, we're not economically valuable to a for-profit healthcare system. So, um, often our needs are not considered... I think that designing the technologies in a way that allows for democratized production and allows for more, local production could kinda address a lot of things. ... I also just find value for me as a trans person, understanding my own 
endocrine system, like the, the factories that produce these medicines are my endocrine system. You know, my body is like expanded beyond my body... So there's these things that come out of this work that are helping me to understand, um, aspects of myself and [with] the work that I'm starting to produce really what I want to convey is like helping people to understand their bodies better."

The interest in exploring how structures of power interact with our bodies through bioart was also present - in P7's work that also interrogates gender politics but from an ecofeminist perspective, that connects questions of personal agency and autonomy to broader issues of environmental justice:

"My work is focused on hormones, and it also intersects with body and gender politics and also environmental toxicity .... thinking about how our bodies are being controlled and managed and also mutated by these molecules. So I would say that my work is also very feminist as someone who is part of this biohacking - global, larger biohacking network, I am very interested in access and also thinking about these ideas of democratization and decentralization and also how all the scientific fields are very dominated by the white male perspective. And so my work tries to kind of clear that perspective."

They further described how their perspectives have shifted as a result of their identity work through their art practice:

"When I first started researching about hormones, especially estrogen, I was more thinking about access to birth control pills and contraceptives or hormone replacement therapy or gender transition therapy. So I was thinking about all those bodies that have access and the ones that don't have access and also has hormones or need to basically support our binary system of genders, having only male and female, and how bodies that are existing in between are either denied of hormones, or they're forced to take hormones... And then the more my research developed, the more I realized that hormones are already all around us as a form of pollution and just really open up the sexes a lot bigger to include all bodies because all of us are exposed to these toxic policies: ... capitalism, agricultural industries, petrochemical, pharmaceutical industry. So, it's really about your agency, your body sovereignty, how much control, and how much consent you have accepting these molecules into your body."

P8 also echoed this focus on critiquing or uncovering pervasive systems of power in their work:

"I'm really drawn even more to the question of power. Um, and I think we're in a moment where disciplinary systems and structures of control, that like really overlap with systems of oppression are kind of moving deeper and deeper into the body and, and into cells even, right? Like on a molecular level. Um, and I saw, I see genetic modification as a technology of control ... I think that's like the main thing that drives me to work with biology is, um, thinking about these new tools that can enable power and systems of control to be more pervasive and simultaneously more invisible."

Our participants' descriptions of using bioart as a way to reflect on, critique and interrogate structures of power and their relationship with individual bodies and identities is in-line with what Vaage described previously as art's ability to create opportunities for audience member to critically examine and develop their moral frameworks [48]. 


\subsubsection{Sparking Dialogue and Cultural Production}

P12 explained that the importance of artists engaging in biology is that they do not just seek to understand the biological processes, as perhaps a scientist does, but they also seek to understand how the scientific practices fit into the social context.

"Bioartists are much more involved in art as a means of cultural production. Uh, so we're not just designing something or making something, but we're interested in the social context. We're interested in a continuum of ideas that starts in the history of an idea often, centuries ago, to current political situations to using these two things as a springboard for envisioning the future ... As a bio artist, you're rooted in this cultural history, the social history, and you're also very involved in envisioning the context in which technological innovation can be used and what is a multidisciplinary viewpoint to that knowledge base."

P8 also spoke about using their work as a bioartist to critique complex cultural and social histories in a way that would capture the attention of an audience:

"My critiques are focused on the way that advancements are made and particularly the patent system... which is a colonial structure that was exported from Europe and forcibly imposed on many countries around the world ... The way that patent system is used to just kind of like concentrate power and wealth by owning molecules and organisms and things like that. So, I think that that's also a really complicated topic to address in bioart or with art and science because it's so fucking boring ... And I'm like, how do I communicate this in a way that is more invigorating and interesting? I'm thinking about the parallels between imposed binary gender, which was kind of a colonial project around the world, and bio piracy and these hierarchies that map the value of different bodies. And trying to find ways to process all of that together ... so that that knowledge could maybe help find other ways that are not so fucked up."

P12 saw the role of artists as distinct from researchers and scientists, which often seeks to find definitive answers to questions. P12 explained the role of artists in not necessarily taking a stance for or against something, but in presenting a dialogue and forcing society to confront important questions:

"Even if you're doing politically based art, idea-based or ethical, often it's important to just insert yourself in the dialogue. Your conclusion is not one side or the other... it's a strategic move, you don't divide it into either/or dialogue. Art is a question. It's not an answer.... it's our obligation to be, as cultural makers and thinkers, to take our skill set, and be involved in those dialogues."

This was also echoed by P7 "I guess my motivations are-they go beyond the material. So, my work is not only about the technical or scientific aspects, but my motivations are more on the political side .... I think just avoiding the kind of reductionist thinking and also trying to have a more critical eye ...I saw other really cool projects [at a previous institution], but there were very few that went beyond just being cool. I felt like a lot of the scientists weren't thinking about what are the actual sociopolitical implications of this technology?"

P1 extended this critique also to bioart itself and stated that it is important to interrogate the reasons for creating bioart, and noted the way that some artists create for the purpose of shock value, reflecting the privilege they already had in society: 
"I mean in a way, sometimes I feel a little disturbed about bioart... unless it's kind of like engaging with critical histories of bios, you know, kind of like biogenetics and like this kind of work, dealing with the processes and like what it has entailed... it's kind of creepy. ... I guess I feel like [for] a lot of transhumanist artists, it's like, okay, but like why? And it's always like white dudes who are doing this work who already get to be like more human than other humans, you know?"

Finally, P7 noted how through their work, they are able to facilitate the creation of an "intimate knowledge around materials" in their workshop participants in order to spark thoughts and dialogue for them:

"I think for participants that I've worked with in workshops, for them to see hormones extracted from their urine is super, super, I don't know, shocking and surprising and kind of like groundbreaking for them ... And I think that's one of the strengths of working in maker, hacker, open-source theme is that you are able to take things apart yourself, take apart black boxes, and create new questions around that... I want people to walk away with knowledge of how to try it at home themselves."

These perspectives show that bioartists saw their practice as distinct, and yet in dialogue, with biology or design, and as a tool for cultural production and dialogue.

\section{DISCUSSION}

\subsection{Hybrid Living Interfaces for Engagement and Learning}

Our findings show that bioartists, educators and community organizers who work at the intersection of art and biology, view living organisms as particularly rich sources of knowledge and inspiration, as well as, capable to engage the public in transdisciplinary and often ethically-oriented conversations about science, technology, art, and social structures. These characteristics may be of particular interest to the HCI community where design materials, processes, and outcomes are often interrogated as sites of innovation. These are in line with previous research that has argued for the creation of "bio-electronic assemblies" [29] and "living media interfaces" [39] to critically explore design possibilities and engage diverse communities in educational and creative experiences. Such hybrid interfaces offer exciting design opportunities to engage users through embodying a shared experience of "vitality" [40], offering opportunities for reflection, learning and critical action.

Our research also underlies a particularly important concern shared between bioartists and the Sustainable HCI $[8,12]$ movement: that of ecological sustainability and environmental awareness. There are increasingly voices in the HCI research and design communities that advocate for considering complex ecological, environmental and socio-political issues when designing new systems. Our participants also described many instances where their work requires reflection and problem-solving in the face of global challenges. Examples ranged from the use of biofabrication techniques for making biodegradable furniture and objects to the use of biomimicry in architecture and other aspects of the built environment. Several participants voiced concerns over waste in the scientific community, specifically plastic waste in labs. These concerns parallel similar ones in the technology design community as well, warranting the exploration of sustainable alternatives. These findings point to an opportunity to use insights from bioartists to interrogate negative patterns of consumption that currently exist in the design

and proliferation of new technologies. We must resist design for novelty sake and ensure a meaningful exploration of reshaping these patterns in a way that is truly impactful on ecological problems of technology waste. 
Additionally, similar to concerns raised previously in the Animal Computer Interaction research community (e.g., $[39,45]$ ), our participants identified a need to consider the agency of living media when brainstorming possible solutions that involve them. For example, as we seek to find solutions to problems of sustainability, the idea of using organic sustainable materials in production seems a promising notion. However, if ideas such as a lamp lit by bioluminescent organisms were to become feasible, should the agency of these organisms be considered? Would their removal from their natural habitats be considered a violation of their agency? Or would the benefits of using sustainable materials, i.e. reducing plastic waste in the oceans, be a validation of this type of cohabitation with living organisms in the built environment? We believe there are further possibilities for conversation about these "valuetensions" [16] between the HCI and bioart communities.

\subsection{Transdisciplinary Collaborations at the Seams}

Our findings show a need for cross-disciplinary collaboration between scientists, designers, and bioethicists in order to ensure that living organisms are not exploited. Previously, Kuznetsov et al. found that DIYbio operates across intersections - or seams - between professional science, hacker subcultures, and the general public [29]. Several of our bioartists participants (P2, P3, P6, and P12) emphasized successful collaborations they had with scientists and scientific organizations. We build on this notion to emphasize the importance of exploring possibilities for collaboration between HCI researchers and practitioners, bioartists, and scientists, to explore novel directions in utilizing living media in interface design.

In addition to the potential for innovation and problem-solving these collaborations can also help with the inclusion of a diversity of voices in the development of new interfaces. As some participants pointed out, technologies are not neutral; they are biased, intentionally or not, by those who design them. This perspective echoes similar well-recognized value-sensitive stances in HCI [16,46]. Ensuring that there are practitioners from the worlds of art, science, and technology working together in the design of living media interfaces is imperative to fostering an environment where the needs of all potential users are considered, as well as recognizing the possible negative implications for some.

\subsection{Bioart as a Site of Interrogation}

Participants repeatedly mentioned a need for ongoing dialogue and a critical process of reflecting on one's work with living organisms to ensure that projects are undertaken in an ethical manner. As some participants pointed out, an effective way to accomplish this is through collaboration and acting as part of a community; working with people in other fields and discussing specific ethical dilemmas that may arise using current ethical understanding can lead to fewer mistakes. This stance recognizes the dynamic and complex nature of ethical questions and the need for living community resources and guidelines to help practitioners. Similar to practices observed in previous research [29], two community lab organizer participants described how a first step in setting up their spaces was to put into place a safety advisory board, as well as, written safety policies and resources to ensure the safety of the organisms and processes they work with. As HCI researchers and practitioners start exploring the space at the intersection of computing and biology, developing such practices is crucial. These efforts can take the form of creating safety policies to shape the practices in the lab, or a system of vetting projects that would include an transdisciplinary group of advisors and stakeholders.

On a more philosophical level, our findings show that bioart has been and continues to be a site of exploration and interrogation of sociopolitical and ethical concerns. Our participants grappled with questions of colonialism, 
power, gender, nationality, access, and agency. These are concerns that the DIS and HCI communities are also increasingly engaged in $[5,43]$. In the future, approaches and perspectives of these communities may combine with and complement each other to form nuanced and effective lens for investigating emerging sociopolitical and ethical dilemmas.

\section{CONCLUSION AND FUTURE WORK}

We have provided a brief introduction to bioart and discussed opportunities for collaboration between artists, designers and community lab organizers who works with living organisms, and HCI researchers and practitioners. In interviews with 12 bioartists, community biology lab organizers, and educators, participants described how they used artistic practices as tools for engagement and collaboration, viewed living organisms as sources of inspiration and knowledge, and engaged with complex ethical dilemmas through their practice. We further discussed how these perspectives can inform future work in HCI by offering novel opportunities for engagement, reflection and inquiry. Additionally, our findings show that working meaningfully with living organisms requires a continuous weighing of possible benefits of such undertaking against its potentials for harm, and a willingness to grapple with the larger sociotechnical histories of biotechnology and science.

The current study demonstrates the diversity and wealth of knowledge in the bioart community and encourages HCI researchers and practitioners to pursue opportunities for transdisciplinary collaborations in the future. In the current study, all but one of our participants were situated in the United States. In the future, we plan to include a larger number of participants from different countries and backgrounds. Our future plans also include studying the perspectives of biodesigners and amateur DIYbio enthusiasts to further investigate their perspectives on the possibilities and limitations of explorations at the intersection of biology and HCI. Finally, we plan to pursue collaborative hands-on research with bioartists to explore possibilities for creating future hybrid living media interfaces.

\section{ACKNOWLEDGMENTS}

We would like to thank our participants for sharing their valuable insights and experiences.

\section{REFERENCES}

[1] Mirela Alistar and Margherita Pevere. 2020. Semina Aeternitatis: Using Bacteria for Tangible Interaction with Data. In Extended Abstracts of the 2020 CHI Conference on Human Factors in Computing Systems (CHI EA' 20), Association for Computing Machinery, New York, NY, USA, 1-13. DOI:https://doi.org/10.1145/3334480.3381817

[2] American Society for Microbiology. ASM Agar Art Contest | Home. ASM.org. Retrieved December 30, 2020 from https://asm.org/Events/ASM-Agar-Art-Contest/Home

[3] Carolyn Angleton. 2019. In pursuit of variegation: Art as research-based collaboration. Antennae Spring 2019,47 (2019), $119-134$.

[4] Jeffrey Bardzell. 2018. Danto' s Artworld: Art--and Design--as Inquiry. In Critical Theory and Interaction Design. MIT Press, Cambridge, MA, 529-558.

[5] Shaowen Bardzell. 2010. Feminist HCI: taking stock and outlining an agenda for design. In Proceedings of the SIGCHI Conference on Human Factors in Computing Systems (CHI’ 10), Association for Computing Machinery, New York, NY, USA, 1301-1310. DOI:https://doi.org/10.1145/1753326.1753521

[6] Shaowen Bardzell, Jeffrey Bardzell, and Sarah Ng. 2017. Supporting Cultures of Making: Technology, Policy, Visions, and Myths. In Proceedings of the 2017 CHI Conference on Human Factors in Computing Systems (CHI '17), Association for Computing Machinery, New York, NY, USA, 6523-6535. DOI:https://doi.org/10.1145/3025453.3025975

[7] Erich Berger, Kasperi Mäki-Reinikka, Kira O' Reilly, and Helena Sederholm (Eds.). 2020. Art as we don' $t$ know it. Aalto University.

[8] Eli Blevis. 2007. Sustainable interaction design: invention \& disposal, renewal \& reuse. In Proceedings of the SIGCHI Conference on Human Factors in Computing Systems - CHI O O7, ACM Press, San Jose, California, USA, 503-512. DOI:https://doi.org/10.1145/1240624.1240705

[9] Joachim Boldt. 2018. Machine metaphors and ethics in synthetic biology. Life Sciences, Society and Policy 14, 1 (June 2018$), 12$. DOI:https://doi.org/10.1186/s40504-018-0077-y 
[10] Oron Catts and Ionat Zurr. 2008. The ethics of experiential engagement with the manipulation of life. In Tactical Biopolitics: Art, Activism and Technoscience, Beatriz da Costa and Kavita Philip (eds.). The MIT Press. DOI:https://doi.org/10.7551/mitpress/7494.003.0010

[11] Adrian David Cheok, Roger Thomas Kok, Chuen Tan, Owen Noel Newton Fernando, Tim Merritt, and Janyn Yen Ping Sen. 2008. Empathetic living media. In Proceedings of the 7th ACM conference on Designing interactive systems (DIS '08), Association for Computing Machinery, New York, NY, USA, 465-473. DOI:https://doi.org/10.1145/1394445.1394495

[12] Carl DiSalvo, Phoebe Sengers, and Hrönn Brynjarsdóttir. 2010. Mapping the landscape of sustainable HCI. In Proceedings of the SIGCHI Conference on Human Factors in Computing Systems (CHI ' 10), Association for Computing Machinery, New York, NY, USA, 1975 -1984. DOI:https://doi.org/10.1145/1753326.1753625

[13] Nicola J Fawcett and Anna Dumitriu. 2018. Bacteria on display-can we, and should we? Artistically exploring the ethics of public engagement with science in microbiology. FEMS Microbiology Letters 365, fny101 (June 2018). DOI:https://doi.org/10.1093/femsle/fny101

[14] Owen Noel Newton Fernando, Adrian David Cheok, Tim Merritt, Roshan Lalintha Peiris, Charith Lasantha Fernando, Nimesha Ranasinghe, Inosha Wickrama, Kasun Karunanayaka, Tong Wei Chua, and Christopher Aldo Tandar. 2009. Babbage Cabbage: Empathetic Biological Media. VRIC Laval Virtual Proceedings (2009), 363-366.

[15] Piyum Fernando, Matthew Pandelakis, and Stacey Kuznetsov. 2016. Practicing DIYBiology In An HCI Setting. In Proceedings of the 2016 CHI Conference Extended Abstracts on Human Factors in Computing Systems (CHI EA'16), Association for Computing Machinery, New York, NY, USA, 2064-2071. DOI:https://doi.org/10.1145/2851581.2892325

[16] Batya Friedman and David Hendry. 2019. Value sensitive design: shaping technology with moral imagination. The MIT Press, Cambridge, Massachusetts.

[17] Gilad Gome, Julian Waksberg, Andrey Grishko, Iddo Yehoshua Wald, and Oren Zuckerman. 2019. OpenLH: Open Liquid-Handling System for Creative Experimentation with Biology. In Proceedings of the Thirteenth International Conference on Tangible, Embedded, and Embodied Interaction (TEI' 19), Association for Computing Machinery, New York, NY, USA, 55-64. DOI:https://doi.org/10.1145/3294109.3295619

[18] Casey Grote, Evan Segreto, Johanna Okerlund, Robert Kincaid, and Orit Shaer. 2015. Eugenie: Multi-Touch and Tangible Interaction for Bio-Design. In Proceedings of the Ninth International Conference on Tangible, Embedded, and Embodied Interaction (TEI ' 15), Association for Computing Machinery, New York, NY, USA, 217-224. DOI:https://doi.org/10.1145/2677199.2680605

[19] Foad Hamidi and Melanie Baljko. 2014. Rafigh: an edible living media installation. In Proceedings of the 8th International Conference on Tangible, Embedded and Embodied Interaction (TEI ' 14), Association for Computing Machinery, New York, NY, USA, 345 -346. DOI:https://doi.org/10.1145/2540930.2555209

[20] Hayden Harvey, Molly Havard, David Magnus, Mildred K. Cho, and Ingmar H. Riedel - Kruse. 2014. Innocent Fun or "Microslavery" ? An ethical analysis of biotic games. Hastings Center Report 44, 6 (2014), 38-46. DOI:https://doi.org/10.1002/hast.386

[21] David Holstius, John Kembel, Amy Hurst, Peng-Hui Wan, and Jodi Forlizzi. 2004. Infotropism: living and robotic plants as interactive displays. In Proceedings of the 5th conference on Designing interactive systems: processes, practices, methods, and techniques (DIS ' 04), Association for Computing Machinery, New York, NY, USA, 215 -221. DOI:https://doi.org/10.1145/1013115.1013145

[22] Eduardo Kac. 1999. Genesis. Retrieved from http://www.ekac.org/geninfo.html

[23] Eduardo Kac (Ed.). 2007. Signs of life: bio art and beyond. MIT Press, Cambridge, Mass.

[24] Yasmin Kafai, Orkan Telhan, Karen Hogan, Debora Lui, Emma Anderson, Justice T. Walker, and Sheri Hanna. 2017. Growing Designs with biomakerlab in High School Classrooms. In Proceedings of the 2017 Conference on Interaction Design and Children (IDC ' 17), Association for Computing Machinery, New York, NY, USA, 503-508. DOI:https://doi.org/10.1145/3078072.3084316

[25] Yasmin Kafai and Justice T. Walker. 2020. Twenty Things to Make with Biology. In Proceedings of the 2020 Constructionism Conference, Dublin, Ireland, 598-606.

[26] cindy lin kaiying, Silvia Lindtner, and Stefanie Wuschitz. 2019. Hacking Difference in Indonesia: The Ambivalences of Designing for Alternative Futures. In Proceedings of the 2019 on Designing Interactive Systems Conference (DIS ' 19), Association for Computing Machinery, New York, NY, USA, 1571-1582. DOI:https://doi.org/10.1145/3322276.3322339

[27] Stacey Kuznetsov, Cassandra Barrett, Piyum Fernando, and Kat Fowler. 2018. Antibiotic-Responsive Bioart: Exploring DIYbio as a Design Studio Practice. In Proceedings of the 2018 CHI Conference on Human Factors in Computing Systems (CHI' 18), Association for Computing Machinery, New York, NY, USA, 1-14. DOI:https://doi.org/10.1145/3173574.3174037

[28] Stacey Kuznetsov, Carrie Doonan, Nathan Wilson, Swarna Mohan, Scott E. Hudson, and Eric Paulos. 2015. DIYbio Things: Open Source Biology Tools as Platforms for Hybrid Knowledge Production and Scientific Participation. In Proceedings of the 33rd Annual ACM Conference on Human Factors in Computing Systems (CHI' 15), Association for Computing Machinery, New York, NY, USA, 4065 -4068. DOI:https://doi.org/10.1145/2702123.2702235

[29] Stacey Kuznetsov, Alex S. Taylor, Tim Regan, Nicolas Villar, and Eric Paulos. 2012. At the seams: DIYbio and opportunities for HCI. In Proceedings of the Designing Interactive Systems Conference (DIS ' 12), Association for Computing Machinery, New York, NY, USA, 258267. DOI:https://doi.org/10.1145/2317956.2317997

[30] Andrew Lapworth. 2015. Beyond Bifurcation: Thinking the Abstractions of Art-Science after A. N. Whitehead. TRANSFORMATIONS Journal of Media \& Culture 26 (2015), 1-12.

[31] Andrew Lapworth. 2015. Habit, art, and the plasticity of the subject: the ontogenetic shock of the bioart encounter. cultural geographies 22, 1 (January 2015), 85-102. DOI:https://doi.org/10.1177/1474474013491926

[32] Andrew Lapworth. 2016. Theorizing Bioart Encounters after Gilbert Simondon. Theory, Culture \& Society 33, 3 (May 2016), 123-150. DOI:https://doi.org/10.1177/0263276415580173

[33] Andrew Lapworth. 2020. Gilbert Simondon and the Technical Mentalities and Transindividual Affects of Art-science. Body \& Society 26, 1 (March 2020), 107-134. DOI:https://doi.org/10.1177/1357034X19882750

[34] Shaun Lawson, Ben Kirman, Conor Linehan, Tom Feltwell, and Lisa Hopkins. 2015. Problematising Upstream Technology through Speculative Design: The Case of Quantified Cats and Dogs. In Proceedings of the 33rd Annual ACM Conference on Human Factors in Computing Systems (CHI ' 15), Association for Computing Machinery, New York, NY, USA, 2663-2672. DOI:https://doi.org/10.1145/2702123.2702260 
[35] Seung Ah Lee, Engin Bumbacher, Alice M. Chung, Nate Cira, Byron Walker, Ji Young Park, Barry Starr, Paulo Blikstein, and Ingmar H. Riedel-Kruse. 2015. Trap it! A Playful Human-Biology Interaction for a Museum Installation. In Proceedings of the 33rd Annual ACM Conference on Human Factors in Computing Systems (CHI' 15), Association for Computing Machinery, New York, NY, USA, 2593 -2602. DOI:https://doi.org/10.1145/2702123.2702220

[36] Clara Mancini. 2017. Towards an animal-centred ethics for Animal-Computer Interaction. International Journal of Human-Computer Studies 98, (February 2017), 221-233. DOI:https://doi.org/10.1016/j.ijhcs.2016.04.008

[37] Marta de Menezes. 2000. Nature? Retrieved from https://martademenezes.com/portfolio/projects/

[38] Marta de Menezes. 2015. Biology as a new media for art: An art research endeavour. Technoetic Arts 13, 1-2 (June 2015), 115-123. DOI:https://doi.org/10.1386/tear.13.1-2.115_1

[39] Timothy Merritt, Foad Hamidi, Mirela Alistar, and Marta DeMenezes. 2020. Living media interfaces: a multi-perspective analysis of biological materials for interaction. Digital Creativity 31, 1 (January 2020), 1-21. DOI:https://doi.org/10.1080/14626268.2019.1707231

[40] Robert Mitchell. 2010. Bioart and the vitality of media. University of Washington Press, Seattle. Retrieved from http://site.ebrary.com/id/11137375

[41] William Myers. 2012. Bio design: nature, science, creativity. Museum of Modern Art: Distributed in the United States and Canada by ARTBOOK/D.A.P, New York.

[42] William Myers. 2015. Bio art: altered realities. Thames \& Hudson, New York, New York.

[43] Ihudiya Finda Ogbonnaya-Ogburu, Angela D.R. Smith, Alexandra To, and Kentaro Toyama. 2020. Critical Race Theory for HCI. In Proceedings of the 2020 CHI Conference on Human Factors in Computing Systems (CHI ' 20), Association for Computing Machinery, New York, NY, USA, 1-16. DOI:https://doi.org/10.1145/3313831.3376392

[44] Marietta Radomska. 2017. Non/living Matter, Bioscientific Imaginaries and Feminist Technoecologies of Bioart. Australian Feminist Studies 32, 94 (2017), 377-394. DOI:https://doi.org/10.1080/08164649.2017.1466649

[45] Charlotte Robinson, Clara Mancini, Janet van der Linden, Claire Guest, Lydia Swanson, Helen Marsden, Jose Valencia, and Brendan Aengenheister. 2015. Designing an emergency communication system for human and assistance dog partnerships. In Proceedings of the 2015 ACM International Joint Conference on Pervasive and Ubiquitous Computing (UbiComp ' 15), Association for Computing Machinery, New York, NY, USA, 337-347. DOI:https://doi.org/10.1145/2750858.2805849

[46] Phoebe Sengers, Kirsten Boehner, Shay David, and Joseph "Jofish" Kaye. 2005. Reflective design. In Proceedings of the 4th decennial conference on Critical computing: between sense and sensibility (CC' 05), Association for Computing Machinery, New York, NY, USA, 49 58. DOI:https://doi.org/10.1145/1094562.1094569

[47] Elizabeth R. Straughan. 2019. A touching experiment: Tissue culture, tacit knowledge, and the making of bioart. Transactions of the Institute of British Geographers 44, 2 (June 2019), 214-225. DOI:https://doi.org/10.1111/tran.12272

[48] Nora S. Vaage. 2016. What Ethics for Bioart? Nanoethics 10, 1 (April 2016), 87-104. DOI:https://doi.org/10.1007/s11569-016-0253-6

[49] Michelle Westerlaken and Stefano Gualeni. 2016. Becoming with: towards the inclusion of animals as participants in design processes. In Proceedings of the Third International Conference on Animal-Computer Interaction (ACI' 16), Association for Computing Machinery, New York, NY, USA, 1-10. DOI:https://doi.org/10.1145/2995257.2995392

[50] Lining Yao, Jifei Ou, Chin-Yi Cheng, Helene Steiner, Wen Wang, Guanyun Wang, and Hiroshi Ishii. 2015. bioLogic: Natto Cells as Nanoactuators for Shape Changing Interfaces. In Proceedings of the 33rd Annual ACM Conference on Human Factors in Computing Systems (CHI' 15), Association for Computing Machinery, New York, NY, USA, 1 -10. DOI:https://doi.org/10.1145/2702123.2702611

[51] Ali K. Yetisen, Joe Davis, Ahmet F. Coskun, George M. Church, and Seok Hyun Yun. 2015. Bioart. Trends in Biotechnology 33, 12 (December 2015), 724-734. DOI:https://doi.org/10.1016/j.tibtech.2015.09.011

[52] Ionat Zurr and Oron Catts. 2003. Are the Semi-Living semi-good or semi-evil? Technoetic Arts 1, 1 (March 2003), 47-60. DOI:https://doi.org/10.1386/tear.1.1.47/0 